\title{
Genic SNP markers and legume synteny reveal candidate genes underlying QTL for Macrophomina phaseolina resistance and maturity in cowpea [Vigna unguiculata (L) Walp.]
}

Wellington Muchero ${ }^{1,3}$, Jeffrey D Ehlers ${ }^{2}$, Timothy J Close ${ }^{2}$, Philip A Roberts ${ }^{1 *}$

\begin{abstract}
Background: Macrophomina phaseolina is an emerging and devastating fungal pathogen that causes significant losses in crop production under high temperatures and drought stress. An increasing number of disease incidence reports highlight the wide prevalence of the pathogen around the world and its contribution toward crop yield suppression. In cowpea [Vigna unguiculata (L) Walp.], limited sources of low-level host resistance have been identified, the genetic basis of which is unknown. In this study we report on the identification of strong sources of host resistance to $M$. phaseolina and the genetic mapping of putative resistance loci on a cowpea genetic map comprised of gene-derived single nucleotide polymorphisms (SNPs) and amplified fragment length polymorphisms (AFLPs).

Results: Nine quantitative trait loci (QTLs), accounting for between 6.1 and $40.0 \%$ of the phenotypic variance $\left(R^{2}\right)$, were identified using plant mortality data taken over three years in field experiments and disease severity scores taken from two greenhouse experiments. Based on annotated genic SNPs as well as synteny with soybean (Glycine max) and Medicago truncatula, candidate resistance genes were found within mapped QTL intervals. QTL Mac-2 explained the largest percent $R^{2}$ and was identified in three field and one greenhouse experiments where the QTL peak co-located with a SNP marker derived from a pectin esterase inhibitor encoding gene. Maturity effects on the expression of resistance were indicated by the co-location of Mac-6 and Mac-7 QTLs with maturity-related senescence QTLS Mat-2 and Mat-1, respectively. Homologs of the ELF4 and FLK flowering genes were found in corresponding syntenic soybean regions. Only three Macrophomina resistance QTLs co-located with delayed drought-induced premature senescence QTLs previously mapped in the same population, suggesting that largely different genetic mechanisms mediate cowpea response to drought stress and Macrophomina infection.
\end{abstract}

Conclusion: Effective sources of host resistance were identified in this study. QTL mapping and synteny analysis identified genomic loci harboring resistance factors and revealed candidate genes with potential for further functional genomics analysis.

\section{Background}

Macrophomina phaseolina (Tassi) Goid. is a soil-borne deuteromycete fungal pathogen with a worldwide distribution and a host range that includes more than 500 crop and non-crop plant species [1]. The fungus is a generalist pathogen that attacks stressed plants at all

\footnotetext{
* Correspondence: philip.roberts@ucr.edu

'Nematology Dept., University of California-Riverside, 3401 Watkins Drive, Riverside, CA 92521, USA

Full list of author information is available at the end of the article
}

stages of growth causing charcoal rot, seedling damping-off, and ashy stem blight diseases of major and minor crops [1]. Major crops such as soybean, maize, and sorghum as well as some crops of economic importance such as common bean are all known hosts of the pathogen and disease incidence is often associated with high temperatures and drought stress. Recently, there has been a worldwide increase in reports of incidence of the pathogen on diverse crop species [2-8], which could

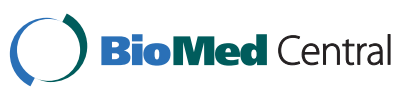


reflect a wider appreciation of the importance of this disease to crop production in drought-prone regions.

In the arid sub-Saharan region of West Africa where cowpea is a crop of major economic importance for resource poor farmers, seedling damping-off and ashy stem blight diseases of cowpea caused by Macrophomina result in significant yield losses [9]. Cowpea is a major crop in this and other arid regions due, in part, to its comparatively high capacity to withstand drought stress and poor soil conditions [10]. The sub-Saharan cowpea production region is characterized by high temperatures (average maximum daily $>30^{\circ} \mathrm{C}$ ) and intermittent rainfall with periods of drought which favor disease development [11]. As a result, cowpea yields remain low (0.2-0.5 t/ha) with Macrophomina infection under drought stress being a major yield-suppressing factor in this agro-ecological zone.

The synergism between disease severity and drought stress is important in breeding programs which are developing drought tolerant cultivars. In cowpea, as in other crops, significant investments continue to be made in the genetic improvement of crop productivity under limited water conditions [12]. However, relatively little emphasis has been placed on the impact of Macrophomina on elite drought-tolerant cultivars in breeding programs. In evaluations of drought-tolerant cowpea genotypes, Ndiaye [11] reported that they were all susceptible to Macrophomina infection. With the exception of the stay-green trait in sorghum [13], there are no reports of genetic overlap between drought tolerance and resistance to Macrophomina.

Host plant resistance-based management of Macrophomina is a potential option for resource-poor farmers. However, in cowpea, only minor sources of resistance have been reported among a few genotypes evaluated in India [14] and Senegal [15], and no studies have identified genomic regions involved in resistance against the pathogen. In other crops, potentially useful minor sources of resistance have been reported in sorghum [16-18], soybean $[19,20]$, and common bean $[21,22]$. Further, studies in common bean suggested that latematuring varieties were more resistant to attack by Macrophomina than early-maturing varieties [22], and similar observations were made in soybean [19] and sorghum [23].

The purpose of this study was to evaluate the levels of resistance against Macrophomina infection in a diverse set of fourteen cowpea genotypes as well as identifying and mapping quantitative trait loci (QTL) associated with resistance to Macrophomina infection in a recombinant inbred line (RIL) population, IT93K-503-1 $\times$ CB46. We used a genetic map developed by merging an AFLP-based map [24] and an expressed sequence tag (EST)-derived single nucleotide polymorphism (SNP) marker-based map [25] for the same population. A consensus genetic linkage map [25] incorporating SNP markers from the IT93K-503-1 × CB46 map and five other RIL populations was utilized for synteny-based candidate gene identification and definition of QTL locations on the cowpea map. Since the IT93K-503-1 × CB46 population was used previously to map QTL for the delayed drought-induced premature senescence and maturityrelated senescence traits [24], the extent of genetic overlap between drought tolerance, maturity, and Macrophomina resistance loci in cowpea was also evaluated.

\section{Results}

\section{Experimental conditions and disease development}

Sufficient disease incidence for differentiation of cowpea genotypes was observed in drought-stressed field experiments conducted in each of the three years. The historically high incidence of Macrophomina-induced ashy stem blight on cowpea in the plots used for the experiments coupled with high temperatures and lack of significant precipitation in the study area enabled adequate disease development to facilitate phenotyping. Average maximum daily temperatures during the experimental periods were 33,32 , and $33^{\circ} \mathrm{C}$ for the 2006,2007 , and 2008 seasons, respectively, whereas average minimum temperatures were 17,16 , and $17^{\circ} \mathrm{C}$, respectively. For the same periods, total precipitation received was 1.0 , 0.5 , and $6.1 \mathrm{~mm}$, respectively.

\section{Phenotyping 14 diverse genotypes}

Based on percent plant mortality, there were reproducible differences in genotypic response to droughtenhanced Macrophomina infection among the diverse set of fourteen cowpea genotypes over the two experiments conducted in 2006 and 2007 (Figure 1). Genotypes IT98K-499-39, Suvita 2, IT93K-503-1 and Mouride were the most resistant to disease development with mortality less than $10 \%$ in both experiments (Figure 1). Bambey 21 was the most susceptible genotype with a mortality of $25-39 \%$, followed by CB46, UCR232 (IT82E-18), 524B, UCR24, and IT84S-2049. Other genotypes exhibited varying levels of intermediate response over both experiments (Figure 1).

\section{Phenotyping RILs}

For the IT93K-503-1 × CB46 RIL population, there was significant correlation between all three field experiments for percent plant mortality based on Spearman Rank analysis $(r \geq 0.3643)$. Further, both greenhouse experiments were correlated $(r=0.6217)$ for disease severity, however correlations between field and greenhouse experiments were mostly insignificant with the exception of the field experiment conducted in 2007 and greenhouse experiment 1 (Table 1). Percent mortality and disease severity 


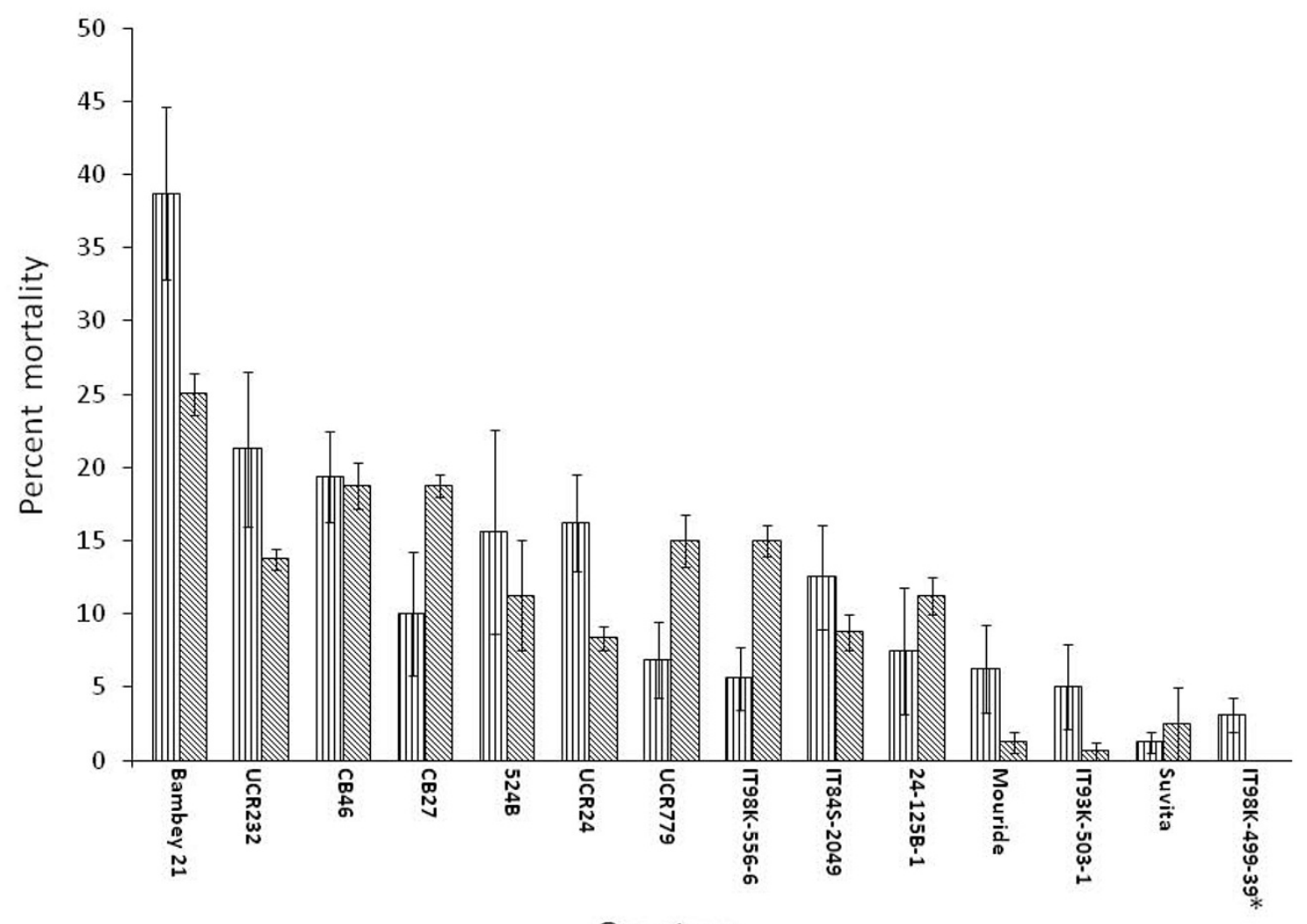

Genotype

Figure 1 Percent plant mortality for fourteen diverse cowpea genotypes exposed to Macrophomina phaseolina under drought stress in field experiments conducted at the University of California Riverside in 2006 (vertical) and 2007 (slanted). See text for complete genotype designations. Bars indicate \pm standard error. ${ }^{*}$ Mortality for IT98K-499-39 was zero in the 2007 experiment.

phenotypic data from all five experiments deviated from normality and there was evidence of transgressive segregation for both resistance and susceptibility to Macrophomina infection indicated by mean phenotypic scores of some lines lying outside the range of the parents (Figure 2).

\section{QTL mapping, associated SNP markers, and synteny}

Eight QTL regions distributed over four linkage groups of the cowpea consensus genetic map were detected in at least two different experiments based on the criteria

Table 1 Spearman Rank correlations for percent mortality and disease severity ratings

\begin{tabular}{lllll}
\hline & $\mathbf{2 0 0 6}$ & $\mathbf{2 0 0 7}$ & $\mathbf{2 0 0 8}$ & Greenhouse 1 \\
\hline 2007 & $0.5508^{* * * *}$ & & & \\
2008 & $0.3643^{* *}$ & $0.3995^{* *}$ & & \\
Greenhouse 1 & $0.1576^{\mathrm{ns}}$ & $0.3377^{*}$ & $0.1332^{\mathrm{ns}}$ & \\
Greenhouse 2 & $0.1844^{\mathrm{ns}}$ & $0.2485^{\mathrm{ns}}$ & $0.0477^{\mathrm{ns}}$ & $0.6217^{* * * *}$ \\
\hline ns $=\mathrm{P}>0.05^{*}=\mathrm{P}<0.05^{* *}=\mathrm{P}<0.01^{* * *}=\mathrm{P}<0.001^{* * * *} \mathrm{P}<0.0001$
\end{tabular}

described in the materials and methods. Seven of the eight QTL derived their favorable allele from the resistant IT93K-503-1 parental genotype whereas the favorable allele for QTL Mac-8 was derived from the susceptible CB46 parental genotype. An additional suggestive QTL, $M a c-4$, did not meet the significance criteria, but was included because peaks were observed at the $63.0 \mathrm{cM}$ and $64.2 \mathrm{cM}$ positions of RIL population linkage group 3 in three separate experiments (Table 2). QTL Mac-2 had the highest significance level as well as $R^{2}$. The same interval was mapped in all three field and one greenhouse experiments, meeting the Kruskal-Wallis significance threshold of 0.005 in each case (Table 2). LOD traces of Mac-2 QTL are shown in Figure 3 for two experiments based on results of the MQM analysis. The $\mathrm{R}^{2}$ for this QTL ranged between $8.0 \%$ and $40 \%$ across four experiments. The QTL peak co-located with SNP marker 1_0853 derived from an EST with a pectin esterase inhibitor annotation. This marker mapped to linkage group 3 

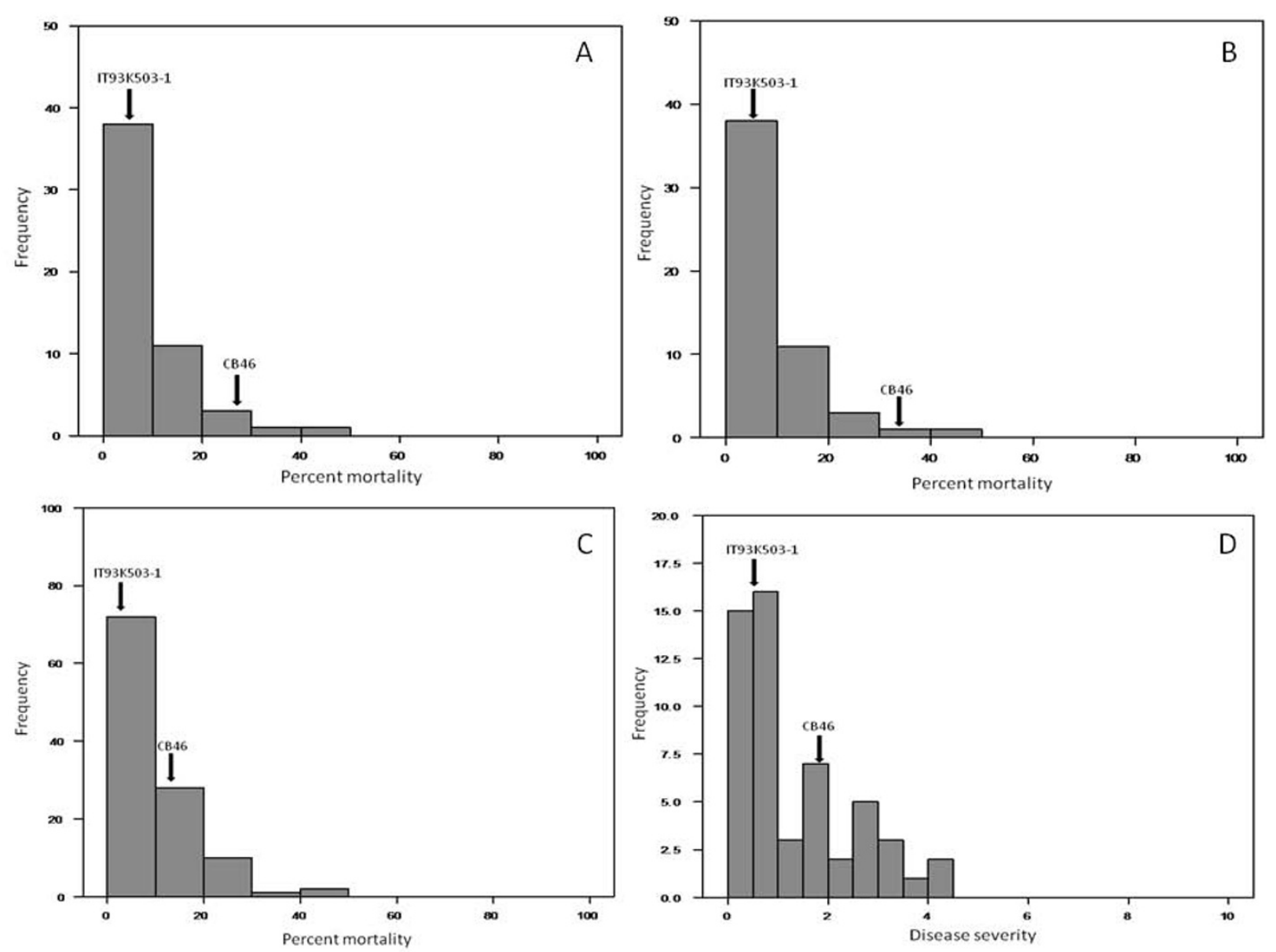

Figure 2 Frequency distribution for percent plant mortality related to drought-enhanced Macrophomina phaseolina infection under field conditions in 2006 (A), 2007 (B), and 2008 (C): and drought-enhanced disease severity ratings under greenhouse conditions averaged over two experiments (D) in a population of recombinant inbred lines developed from a cross between homozygous genotypes IT93K-503-1 and CB46.

of the cowpea consensus map. Comparative genome analysis revealed extensive synteny between the cowpea region carrying the 1_0853 marker on linkage group 3 and a segment of M. truncatula chromosome 4 [25]. Within the M. truncatula region, two copies of pectin esterase inhibitor gene and a pectin esterase virulence target gene exist. Similarly, the corresponding soybean genomic region on chromosome 8 harbors a pectin esterase inhibitor and two copies of a pectin esterase encoding gene. A separate QTL, Mac-3, mapped on the same cowpea linkage group and co-located with SNP marker 1_0604 derived from an EST with a pectin acetylesterase gene annotation (Table 2).

QTL Mac-1 was identified in two field and both greenhouse experiments with $\mathrm{R}^{2}$ estimates between $14.4 \%$ and $20.9 \%$. This QTL mapped within $2.2 \mathrm{cM}$ in three experiments (Table 2). The most consistent loci for this QTL on cowpea linkage group 2 coincided with a MATE efflux family protein encoding gene and was highly syntenic to homeologous regions on G. $\max$ chromosomes 10 and 20. The region on soybean chromosome 10 harbored nine copies of the MATE efflux family protein whereas the chromosome 20 region carried three copies of the gene.

QTLs Mac-6 and Mac-7 co-located with maturityrelated senescence QTLs Mat-2 (AFLP marker interval AGC-CAC7 - AAC-CAA19) and Mat-1 (AFLP marker interval ACG-CAG9 - AGG-CAT1), respectively [24], (Figure 4). In both cases, the Macrophomina resistance allele was associated with lateness in maturity.

For Mac-6, accounting for between $7.7 \%$ and $18.2 \%$ of the phenotypic variance for response to Macrophomina infection, the SNP marker 1_0804, derived from a homo$\log$ of the light harvesting complex PSII (LHCB4.3) gene, co-located with the QTL peak in two of the three experiments in which the QTL was identified (Figure 4). The cowpea region harboring Mac-6 revealed macrosynteny 
Table 2 QTL mapping results based on Kruskal-Wallis (KW) and Multiple-QTL Model mapping (MQM) analysis

\begin{tabular}{|c|c|c|c|c|c|c|c|c|c|c|}
\hline \multirow[b]{2}{*}{ Experiment } & \multirow[b]{2}{*}{ QTL } & \multirow[b]{2}{*}{$\mathrm{LG}^{\dagger}$} & \multirow[b]{2}{*}{$\begin{array}{c}\text { QTL } \\
\text { interval }\end{array}$} & \multirow[b]{2}{*}{$\begin{array}{l}\text { Consensus LG } \\
\text { and map } \\
\text { position }(\mathrm{cM})^{\dagger}\end{array}$} & \multirow[b]{2}{*}{$\begin{array}{l}\text { Marker closest } \\
\text { to QTL peak }\end{array}$} & \multirow{2}{*}{$\begin{array}{c}\text { KW } \\
\begin{array}{c}\text { Significance } \\
\text { level }\end{array}\end{array}$} & \multicolumn{3}{|c|}{ MQM } & \multirow[b]{2}{*}{ Marker annotation } \\
\hline & & & & & & & LOD & $\begin{array}{c}\text { LOD } \\
\text { threshold }\end{array}$ & $R^{2}$ & \\
\hline Riverside 2007 & Mac-1 & 2 & $5.2-21.8$ & $2(77.4)$ & 1_0709 & 0.01 & 1.77 & 2.0 & 14.5 & $\begin{array}{l}\text { MATE efflux family } \\
\text { protein }\end{array}$ \\
\hline Greenhouse 1 & Mac-1 & 2 & $6.8-21.8$ & $2(75.2)$ & 1_0551 & 0.005 & 2.74 & 2.0 & 20.9 & $\begin{array}{l}\text { Endo-xyloglucan } \\
\text { transferase }\end{array}$ \\
\hline Greenhouse 2 & Mac-1 & 2 & $5.2-21.8$ & $2(77.4)$ & 1_0709 & 0.05 & 1.82 & 2.0 & 14.4 & $\begin{array}{l}\text { MATE efflux family } \\
\text { protein }\end{array}$ \\
\hline Riverside 2006 & Mac-2 & 3 & $8.1-25.9$ & $3(1.3)$ & 1_0853 & 0.001 & 3.11 & 2.1 & 26.5 & $\begin{array}{l}\text { Pectin esterase } \\
\text { inhibitor }\end{array}$ \\
\hline Riverside 2007 & Mac-2 & 3 & $8.1-25.9$ & $3(1.3)$ & 1_0853 & 0.0001 & 5.76 & 2.1 & 40.0 & $\begin{array}{l}\text { Pectin esterase } \\
\text { inhibitor }\end{array}$ \\
\hline Riverside 2008 & Mac-2 & 3 & $8.1-25.9$ & $3(1.3)$ & 1_0853 & 0.005 & 1.73 & 2.1 & 8.0 & $\begin{array}{l}\text { Pectin esterase } \\
\text { inhibitor }\end{array}$ \\
\hline Greenhouse 1 & Mac-2 & 3 & $8.1-25.9$ & $3(1.3)$ & 1_0853 & 0.005 & 1.45 & 2.1 & 11.6 & $\begin{array}{l}\text { Pectin esterase } \\
\text { inhibitor }\end{array}$ \\
\hline Riverside 2006 & Mac-3 & 3 & $68.3-84.2$ & $3(42.3)$ & 1_0604 & 0.005 & 1.24 & 2.1 & 10.6 & $\begin{array}{l}\text { Pectin acetylesterase } \\
\text { precursor }\end{array}$ \\
\hline Riverside 2007 & $M a c-3$ & 3 & $58.2-84.2$ & $3(42.3)$ & 1_0604 & 0.005 & 1.16 & 2.1 & 9.7 & $\begin{array}{l}\text { Pectin acetylesterase } \\
\text { precursor }\end{array}$ \\
\hline Riverside 2006 & Mac-4" & 3 & $109.0-116.2$ & $3(64.2)$ & 1_0464 & 0.05 & 1.61 & 2.1 & 13.3 & $\begin{array}{l}\text { Ribosomal protein } \\
\text { L7Ae }\end{array}$ \\
\hline Riverside 2007 & Mac-4" & 3 & $109.0-116.2$ & $3(63.0)$ & 1_0201 & 0.05 & 1.18 & 2.1 & 9.9 & $\begin{array}{l}\text { Cell growth defect } \\
\text { factor } 1\end{array}$ \\
\hline Riverside 2008 & Mac-4" & 3 & $97.9-116.2$ & $3(63.0)$ & 1_0201 & 0.05 & 1.21 & 2.1 & 6.1 & $\begin{array}{l}\text { Cell growth defect } \\
\text { factor } 1\end{array}$ \\
\hline Riverside 2006 & Mac-5 & 11 & $6.1-14.4$ & $3(-)$ & ACA-CAT $13^{\ddagger}$ & 0.005 & 2.26 & 1.5 & 18.1 & - \\
\hline Riverside 2007 & Mac-5 & 11 & $6.1-14.4$ & $3(70.8)$ & 1_0079 & 0.01 & 1.22 & 1.5 & 10.3 & $\begin{array}{l}\text { CA2+- binding protein } \\
1\end{array}$ \\
\hline Riverside 2008 & Mac-5 & 11 & $9.1-13.9$ & $3(74.0)$ & 1_0496 & 0.1 & 1.40 & 1.5 & 6.7 & MLP-like protein 423 \\
\hline Riverside 2006 & Mac-6 & 5 & $17.2-23.2$ & $4(57.5)$ & 1_0699 & 0.01 & 2.27 & 2.1 & 18.2 & $\begin{array}{l}\text { Tropine } \\
\text { dehydrogenase }\end{array}$ \\
\hline Riverside 2007 & Mac-6 & 5 & $8.9-23.2$ & $4(59.3)$ & 1_0804 & 0.005 & 1.99 & 2.1 & 16.2 & $\begin{array}{l}\text { Light harvesting } \\
\text { complex PSII }\end{array}$ \\
\hline Riverside 2008 & Mac-6 & 5 & $7.4-20.5$ & $4(-)$ & ACT-CAT8 & 0.05 & 1.61 & 2.1 & 7.7 & - \\
\hline Riverside 2006 & Mac-7 & 5 & $31.8-49.1$ & $4(41.0)$ & 1_0678 & 0.01 & 2.44 & 2.1 & 19.4 & $\begin{array}{l}\text { UDP- } \\
\text { glycosyltransferase }\end{array}$ \\
\hline Riverside 2007 & Mac-7 & 5 & $27.5-49.1$ & $4(41.0)$ & 1_0678 & 0.0005 & 2.44 & 2.1 & 19.4 & $\begin{array}{l}\text { UDP- } \\
\text { glycosyltransferase }\end{array}$ \\
\hline Riverside 2008 & Mac-7 & 5 & $41.2-53.8$ & $4(34.2)$ & 1_0153 & 0.0005 & 2.91 & 2.1 & 13.3 & $\begin{array}{l}\text { lipase class } 3 \text { family } \\
\text { protein }\end{array}$ \\
\hline Riverside 2006 & Mac-8 & 6 & $28.4-40.0$ & $5(-)$ & AAG-CTC9 & 0.005 & 2.20 & 2.1 & 18.0 & - \\
\hline Riverside 2007 & Mac-8 & 6 & $27.9-43.3$ & $5(29.7)$ & 1_0030 & 0.05 & 1.01 & 2.1 & 8.6 & $\begin{array}{l}605 \text { ribosomal protein } \\
\text { L10 }\end{array}$ \\
\hline Riverside 2008 & Mac-8 & 6 & $29.8-41.2$ & $5(29.7)$ & AAG-CTC9 & 0.005 & 2.64 & 2.1 & 12.1 & - \\
\hline Greenhouse 1 & Mac-8 & 6 & $36.1-44.5$ & $5(29.7)$ & 1_0030 & 0.05 & 1.23 & 2.1 & 9.9 & $\begin{array}{l}605 \text { ribosomal protein } \\
\text { L10 }\end{array}$ \\
\hline Riverside 2008 & Mac-9 & 6 & $53.5-63.2$ & $5(44.6)$ & 1_0032 & 0.005 & 2.12 & 2.1 & 12.1 & $\begin{array}{l}\text { Protein transport } \\
\text { protein SEC61 }\end{array}$ \\
\hline Greenhouse 1 & Mac-9 & 6 & $53.5-71.4$ & $5(40.9)$ & 1_1533 & 0.05 & 1.29 & 2.1 & 10.4 & $\begin{array}{l}\text { Integral membrane } \\
\text { Yip1 family protein }\end{array}$ \\
\hline Greenhouse 2 & Mac-9 & 6 & $53.5-70.7$ & $5(40.9)$ & 1_1533 & 0.05 & 1.01 & 2.1 & 8.3 & $\begin{array}{l}\text { Integral membrane } \\
\text { Yip1 family protein }\end{array}$ \\
\hline
\end{tabular}

${ }^{\dagger}$ LG = IT93K-503-1 $\times$ CB46 RIL population linkage group based on AFLP + SNP map, Consensus LG = corresponding linkage group in the cowpea consensus genetic map, consensus map position represents position of the marker closest to the QTL peak based on mapping in the RIL population.

₹ $\mathrm{CM}$ position on the consensus map and annotations for AFLP markers were not determined.

"Mac-4 was included as a suggestive QTL since it did not meet the significance thresholds in either the Kruskal-Wallis or MQM analysis. 


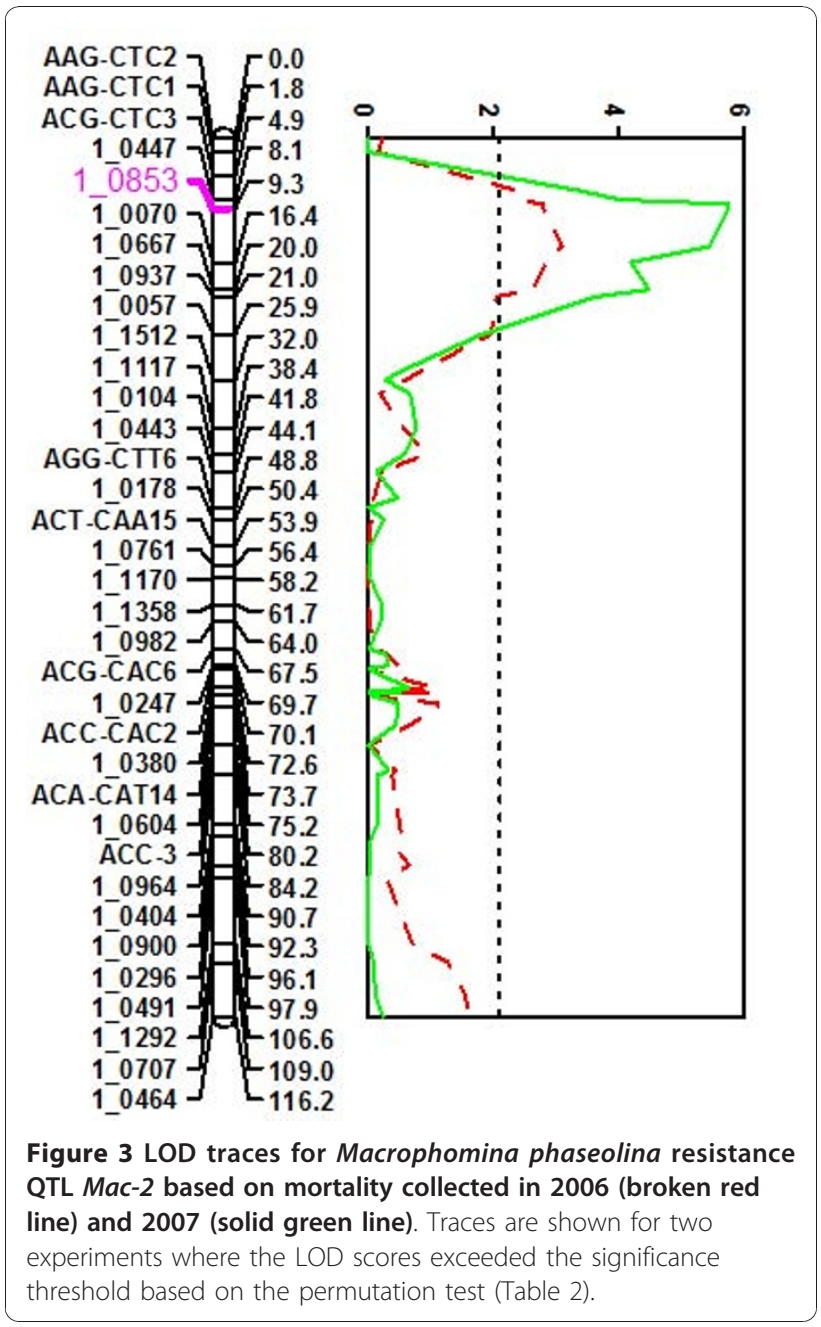

with sections on soybean chromosomes 11 and 18 where copies of the LHCB4.3 gene were found [25]. Within the soybean chromosome 11 region, a homolog of the arginyltransferase (ATE1) delayed senescence gene as well as a homolog of the ELF4 (Early Flowering 4) gene were found contiguous to the LHCB4.3 locus (Table 3) ftp://ftp.jgi-psf. org/pub/JGI_data/Glycine_max/Glyma1/.

QTL Mac-7 was significant in all three field experiments. In the two experiments conducted with 57 RILs, the QTL peak co-located with SNP marker 1_0678 derived from a homolog of the UDP-glucosyltransferase gene (Table 2). Synteny with $M$. truncatula was identified with a region of chromosome 7 where three copies of pectin esterase-related genes were identified http://www.medicago.org. In the other experiment conducted with 108 RILs, the QTL peak mapped $5.8 \mathrm{cM}$ away and co-located with SNP 1_0153 derived from a lipase class 3 family protein-encoding gene. Based on BLAST searches using this EST sequence, no homology was found in M. truncatula, but significant homology

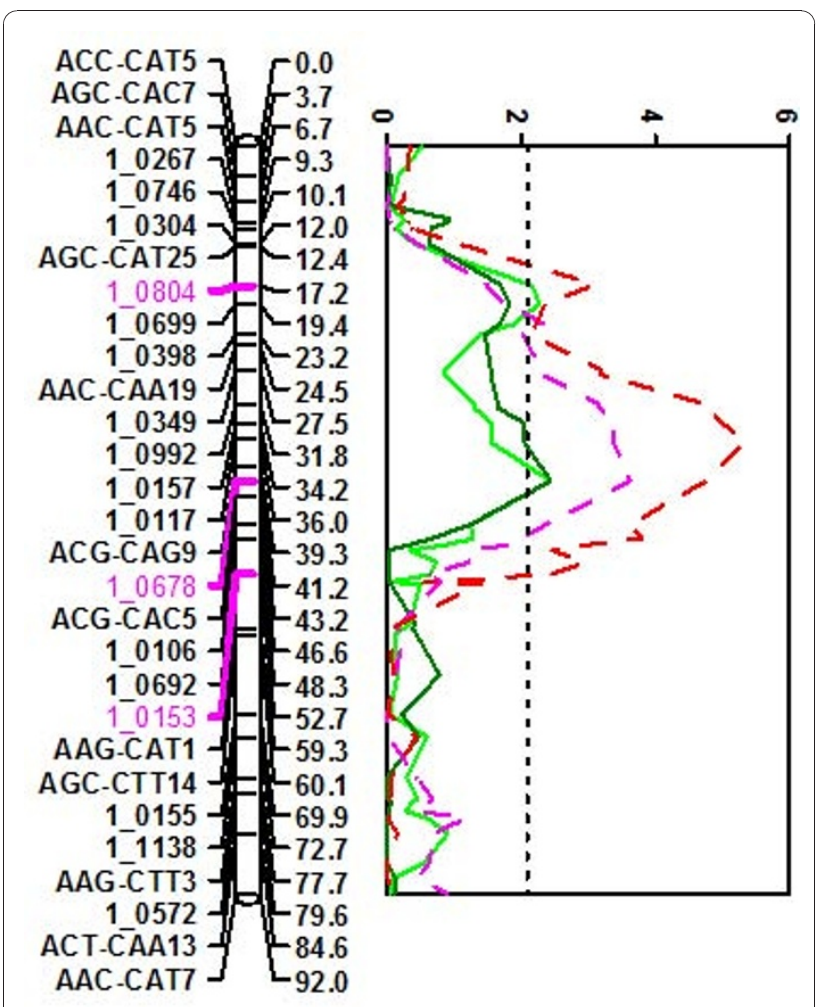

Figure 4 LOD traces showing the co-location of Macrophomina resistance QTL Mac-6 and Mac-7 (solid green lines) with maturity-related senescence QTL Mat-1 and Mat-2 (broken red and magenta lines). Candidate SNP markers are highlighted in magenta color, vertical broken lines illustrate the LOD significance threshold.

was found on soybean chromosome 3. No classic disease resistance associated genes were found near the lipase class 3 protein encoding gene, which was next to homologs of the Photosystem II reaction center W gene. In addition, contiguous loci carrying three copies of genes homologous to the FLK (flowering locus KH domain) were identified. LG7 and LG8 which harbored the two maturity QTL based on the AFLP-only map [24] were consolidated into LG5 of the current RIL map and LG4 of the consensus genetic map as described by Muchero et al [25]. EMBL accession numbers and annotation details of cowpea ESTs harboring QTL-associated SNP markers are given in Table 4.

\section{QTL pyramiding}

Eight QTLs (Mac-1 to Mac-8) were selected for the single and pair-wise analysis based on their consistency in map location across experiments. In general, mean percent mortalities for the null genotypes were higher than genotypes with favorable alleles. However, in the analysis based on single QTLs, only Mac-1, Mac-2 and Mac-7 showed statistically significant differences out of 
Table 3 Soybean gene models and their Arabidopsis annotations within a syntenic region near the 1_0804 locus

\begin{tabular}{|c|c|c|c|c|}
\hline $\begin{array}{l}\text { Soybean } \\
\text { Chromosome }\end{array}$ & $\begin{array}{l}\text { Soybean gene } \\
\text { model }\end{array}$ & $\begin{array}{l}\text { Homologous } \\
\text { cowpea locus }\end{array}$ & E-score & Arabidopsis annotation \\
\hline Gm11 & Glyma11g35090.1 & - & $1.00 \mathrm{E}-174$ & $\begin{array}{l}\text { CHR2V8|COORD:16735456..16738238| similar to proline-rich family protein } \\
\text { [Arabidopsis thaliana] (TAIR:AT3G09000.1) }\end{array}$ \\
\hline Gm11 & Glyma11g35100.1 & - & $1.00 \mathrm{E}-176$ & $\begin{array}{l}\text { CHR5V8|COORD:1712951..1715640| ATE1 (DELAYED LEAF SENESCENCE 1); } \\
\text { arginyltransferase }\end{array}$ \\
\hline Gm11 & Glyma11g35110.2 & - & $1.00 \mathrm{E}-59$ & CHR2V8|COORD:16755237..16756435| yippee family protein \\
\hline Gm11 & Glyma11g35110.1 & - & $1.00 \mathrm{E}-59$ & CHR2V8|COORD:16755237..16756435| yippee family protein \\
\hline Gm11 & Glyma11g35120.1 & - & - & - \\
\hline Gm11 & Glyma11g35130.1 & 1_0804 & $1.00 \mathrm{E}-111$ & $\begin{array}{l}\text { CHR2V8|COORD:16752962..16754268| LHCB4.3 (LIGHT HARVESTING } \\
\text { COMPLEX PSII); chlorophyll binding }\end{array}$ \\
\hline Gm11 & Glyma11g35140.1 & - & 4.00E-24 & $\begin{array}{l}\text { CHR4V8|COORD:16426775..16427836| TAF8 (TBP-ASSOCIATED FACTOR 8); } \\
\text { DNA binding }\end{array}$ \\
\hline Gm11 & Glyma11g35150.1 & - & - & - \\
\hline Gm11 & Glyma11g35160.1 & - & - & - \\
\hline Gm11 & Glyma11g35170.1 & - & $3.00 \mathrm{E}-67$ & $\begin{array}{l}\text { CHR2V8|COORD:16750185..16751533| similar to unknown protein } \\
\text { [Arabidopsis thaliana] (TAIR:AT3G55880.2) }\end{array}$ \\
\hline Gm11 & Glyma11g35180.1 & - & - & - \\
\hline Gm11 & Glyma11g35190.1 & - & - & - \\
\hline Gm11 & Glyma11g35200.1 & - & - & - \\
\hline Gm11 & Glyma11g35210.1 & - & $1.00 \mathrm{E}-149$ & $\begin{array}{l}\text { CHR2V8|COORD:5685088.5687703| ATCHX15 (cation/hydrogen exchanger } \\
\text { 15); monovalent cation:proton antiporter }\end{array}$ \\
\hline Gm11 & Glyma11g35220.1 & - & $6.00 \mathrm{E}-11$ & CHR3V8|COORD:19436813..19438010| SYP122 (syntaxin 122); SNAP receptor \\
\hline Gm11 & Glyma11g35230.1 & - & $2.00 \mathrm{E}-11$ & CHR1V8|COORD:9715602..9720333| RNA helicase, putative \\
\hline Gm11 & Glyma11g35240.1 & - & $1.00 \mathrm{E}-113$ & $\begin{array}{l}\text { CHR3V8|COORD:3511107..3512905| GDSL-motif lipase/hydrolase family } \\
\text { protein }\end{array}$ \\
\hline Gm11 & Glyma11g35240.2 & - & $1.00 \mathrm{E}-113$ & $\begin{array}{l}\text { CHR3V8|COORD:3511107..3512905| GDSL-motif lipase/hydrolase family } \\
\text { protein }\end{array}$ \\
\hline Gm11 & Glyma11g35250.1 & - & $1.00 \mathrm{E}-10$ & $\begin{array}{l}\text { CHR1V8|COORD:6781665.6782015| LCR78/PDF1.4 (Low-molecular-weight } \\
\text { cysteine-rich 78) }\end{array}$ \\
\hline Gm11 & Glyma11g35260.2 & - & 7.00E-71 & CHR1V8|COORD:6585078..6586299| TTN10 (TITAN 10) \\
\hline Gm11 & Glyma11g35260.1 & - & $7.00 \mathrm{E}-71$ & CHR1V8|COORD:6585078.6586299| TTN10 (TITAN 10) \\
\hline Gm11 & Glyma11g35270.1 & - & $7.00 \mathrm{E}-28$ & CHR2V8|COORD:16741623..16741958| ELF4 (EARLY FLOWERING 4) \\
\hline
\end{tabular}

the eight QTLs (Figure 5), and 15 out of the 28 pairwise combinations showed significant differences (Table 5). Percent reductions for the pair-wise combinations ranged from -5.8 to $47.6 \%$ with six combinations resulting in a reduction of mean percent mortality greater than $40 \%$ (Table 5). Five of the six combinations had QTL Mac-7 in common and these ranged from $42.8 \%$ to $47.6 \%$ reduction in mean percent mortality. The remaining $\mathrm{Mac}-2 / \mathrm{Mac}-5$ combination resulted in a $41.0 \%$ percent reduction, and the null genotypes for this combination also had the highest mean percent mortality $(18.8 \% \pm 3.37 \%)$. Individually, Mac-2 and Mac-5 resulted in reductions of mean percent mortality of $19.6 \%$ and $22.5 \%$, respectively, suggesting an additive effect in genotypes carrying both favorable alleles. This QTL combination was chosen for further analysis using the 2006 and 2007 data. The Mac-2/Mac-5 combination resulted in a $65.6 \%$ reduction in mean percent mortality based on 2006 data and 58.5\% for the 2007 data (Figure 6). Although they exhibited the largest reductions on percent mortality, QTL combinations with Mac-7 were not favored for this analysis due to potential linkage or pleiotropic effects of the Mac-7 locus with maturity which may limit its practical use.

\section{Co-location of drought and Macrophomina resistance QTLS}

Co-location was observed between Mac-4, Mac-5, and Mac-9 with seedling drought response QTLs Dro-5, Dro10 , and Dro-7, respectively, which were mapped previously [24]. In each case, the Macrophomina resistance haplotype in these loci corresponded with the haplotype for tolerance to seedling-stage drought stress as measured by delayed drought-induced premature senescence. Soybean genomic regions syntenic to the 3 QTL regions harbored osmotic stress responsive genes such as heat shock, calcium sensing and sodium hypersensitive genes. However, the region syntenic to Mac-5 QTL region also harbored disease resistance/susceptibility genes such as glycoside hydrolase, lipase, pectinase, and pectin esterase genes. 
Table 4 Annotation of cowpea ESTs harboring SNP markers associated with Macrophomina resistance QTL

\begin{tabular}{|c|c|c|c|c|}
\hline SNP marker & Cowpea EST accession number & Best Annotated EMBL hit & E score & Annotation \\
\hline 1_0709 & FF388857 & DQ446394 & $3.00 \mathrm{E}-42$ & Arabidopsis thaliana MATE efflux family protein \\
\hline 1_0551 & FG940166 & BE554813 & 4.90E-92 & Glycine max Endo-xyloglucan transferase \\
\hline 1_0853 & FG876090 & EE127646 & $6.84 \mathrm{E}-74$ & Glycine max Pectinesterase inhibitor \\
\hline 1_0604 & FG841619 & BE190146 & $2.90 \mathrm{E}-72$ & Glycine max Pectinacetylesterase precursor \\
\hline 1_0464 & FF544070 & CA905170 & $6.60 \mathrm{E}-115$ & Phaseolus coccineus Ribosomal protein L7Ae \\
\hline 1_0201 & FG818679 & AB210817 & $1.50 \mathrm{E}-64$ & Arabidopsis thaliana Cell growth defect factor 1 \\
\hline 1_0079 & FG880038 & AF145386 & $3.90 \mathrm{E}-84$ & Phaseolus vulgaris $\mathrm{CA} 2+-$ binding protein 1 \\
\hline 1_0496 & FG909180 & AB027154 & $3.10 \mathrm{E}-96$ & Vigna unguiculata Pathogenesis related protein 3 \\
\hline 1_0699 & FF382329 & BG238363 & $3.30 \mathrm{E}-114$ & Glycine max Tropinone reductase homolog \\
\hline 1_0804 & FC458836 & BQ296449 & $1.90 \mathrm{E}-96$ & Glycine max Putative Chlorophyll binding protein \\
\hline 1_0678 & FG823412 & AB070752 & $1.00 \mathrm{E}-132$ & Vigna angularis Glycosyltransferase \\
\hline 1_0153 & FC457603 & FJ461591 & $9.20 \mathrm{E}-29$ & Brassica napus Chloroplast Lipase \\
\hline 1_0030 & FG935301 & AJ133146 & $1.60 \mathrm{E}-32$ & Persea Americana Fructose-bisphosphate aldolase \\
\hline 1_0032 & FG886549 & CA907484 & $5.80 \mathrm{E}-59$ & Phaseolus coccineus Protein transport protein SEC61 \\
\hline 1_1533 & FF549040 & XP002881680 & $2.00 \mathrm{e}-95$ & Arabidopsis thaliana Integral membrane Yip1 family protein \\
\hline
\end{tabular}

\section{Discussion}

Important sources of genetic resistance to Macrophomina were identified in cowpea genotypes assessed under mild drought-stress conditions. Based on field screening, genotypes IT98K-499-39, Suvita 2, IT93K503-1, and Mouride exhibited the highest levels of resistance and are potential sources of host resistance in management strategies in response to Macrophomina infection.

Screening a RIL population derived from a cross between the resistant IT93K-503-1 and susceptible CB46 genotypes facilitated the genetic analysis of the resistance trait in one of these highly resistant germplasm sources. Our QTL mapping approach took

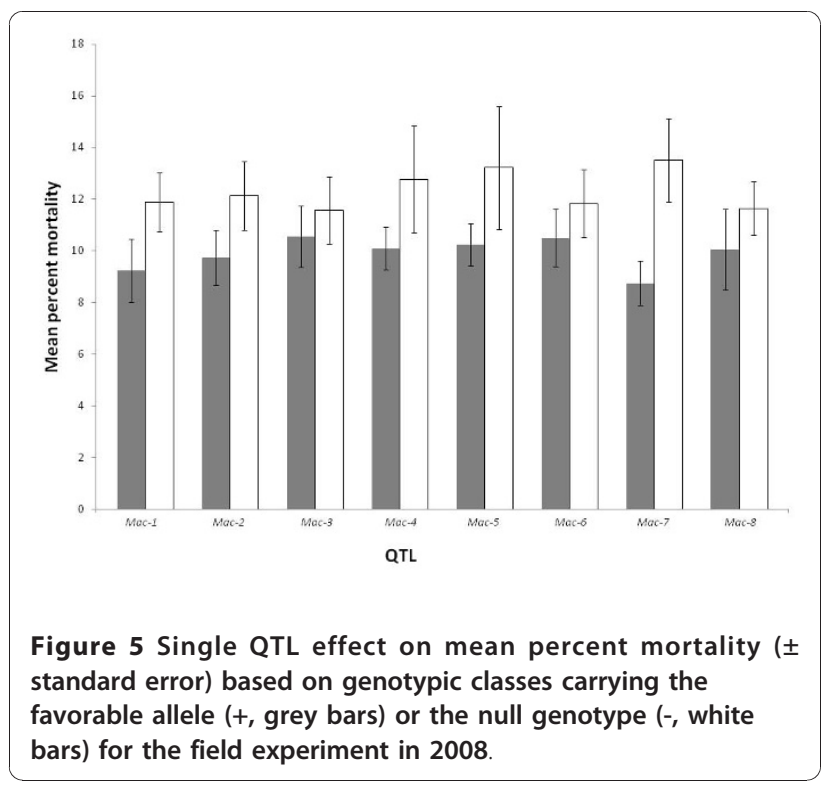

advantage of the recently developed high density EST-derived SNP marker consensus map of cowpea [25] in which the IT93K-503-1 × CB46 RIL was a constituent map. The QTL mapping indicated a quantitative basis of this trait and also transgressive segregation for both resistance and susceptibility. The transgressive lines with higher resistance levels indicate the potential for selecting novel resistance forms in breeding populations in which the susceptible parent contributes to the resistance phenotype.

Furthermore, genic SNP markers with disease resistance gene annotation and disease resistance-associated genes were found in the genomic intervals defined by the QTL and these were located within syntenic regions in soybean and Medicago. Most interestingly, pectin metabolism related genes were identified in three major QTL intervals. The role of plant cell wall polysaccharides, including pectins, in defense against pathogenic microbes has been described [26], and Radha [27] demonstrated that French bean plants infected with Macrophomina had $50 \%$ less pectin compared to healthy ones, an observation attributed to the pectinolytic activity of enzymes released by the pathogen. Examples of the role of pectins in pathogen defense in other systems include the over expression of pectin methylesterase inhibitors in Arabidopsis that resulted in increased resistance to the necrotrophic fungus Botrytis cinerea [28]. Similarly, disrupting a pectin methylesterase gene resulted in reduced virulence of B. cinerea on apple (Malus domestica), grapevine (Vitis vinifera) and Arabidopsis [29]. Since Macrophomina and $B$. cinerea share similar pathogenicity mechanisms involving pectin degradation as described above, these results suggest an important role for pectin-related genes in defense against Macrophomina. However, this cannot be addressed in the present study, and additional 
Table 5 Pair-wise analysis of the effect of QTL combinations on mean percent mortality between genotypic classes

\begin{tabular}{|c|c|c|c|c|c|c|c|}
\hline \multirow[t]{2}{*}{ QTL combination } & \multicolumn{3}{|c|}{ - genotype } & \multicolumn{3}{|c|}{ ++ genotype } & \multirow[t]{2}{*}{$\%$ reduction in mortality } \\
\hline & Mean \% mortality & $\mathbf{N}$ & S.E & Mean \% mortality & $\mathrm{N}$ & S.E & \\
\hline Mac-1/Mac-7 & 14.3 & 30 & 2.07 & 7.5 & 17 & 1.38 & 47.6 \\
\hline Mac-5/Mac-7 & 15.8 & 15 & 3.5 & 8.4 & 42 & 0.83 & 46.8 \\
\hline Mac-2/Mac-7 & 13.7 & 25 & 2.35 & 7.7 & 28 & 1.06 & 43.8 \\
\hline Mac-4/Mac-7 & 15.1 & 19 & 2.97 & 8.5 & 41 & 0.85 & 43.7 \\
\hline Mac-3/Mac-7 & 14.5 & 24 & 2.34 & 8.3 & 24 & 1.38 & 42.8 \\
\hline Mac-2/Mac-5 & 18.8 & 15 & 3.37 & 11.1 & 34 & 1.25 & 41.0 \\
\hline Mac-2/Mac-4 & 17.8 & 16 & 3.45 & 10.9 & 29 & 1.4 & 38.8 \\
\hline Mac-5/Mac-6 & 16.4 & 13 & 4.06 & 10.2 & 28 & 1.23 & 37.8 \\
\hline Mac-1/Mac-4 & 15.6 & 20 & 2.91 & 10 & 18 & 1.56 & 35.9 \\
\hline Mac-1/Mac-5 & 16.3 & 19 & 2.94 & 10.5 & 23 & 1.41 & 35.6 \\
\hline Mac-1/Mac-2 & 12.8 & 39 & 1.69 & 8.6 & 17 & 1.78 & 32.8 \\
\hline Mac-7/Mac-8 & 13.4 & 15 & 3.3 & 9.4 & 33 & 1.23 & 29.9 ns \\
\hline Mac-3/Mac-5 & 14.5 & 16 & 3.2 & 10.2 & 35 & 1.17 & $29.7 \mathrm{~ns}$ \\
\hline Mac-2/Mac-6 & 11.9 & 34 & 1.84 & 8.38 & 23 & 1.15 & 29.6 \\
\hline Mac-4/Mac-6 & 14.7 & 19 & 3.05 & 10.4 & 28 & 1.24 & 29.3 \\
\hline Mac-4/Mac-5 & 13.9 & 21 & 2.91 & 10 & 60 & 0.88 & 28.1 \\
\hline Mac-4/Mac-8 & 15.7 & 9 & 5.07 & 11.4 & 39 & 1.12 & $27.4 \mathrm{~ns}$ \\
\hline Mac-6/Mac-7 & 13.9 & 34 & 1.9 & 10.2 & 33 & 1.22 & 26.6 \\
\hline Mac-3/Mac-4 & 13.1 & 25 & 2.25 & 10 & 37 & 1.07 & $23.7 \mathrm{~ns}$ \\
\hline Mac-5/Mac-8 & 14.9 & 10 & 4.54 & 11.4 & 46 & 1.08 & $23.5 \mathrm{~ns}$ \\
\hline Mac-1/Mac-6 & 13 & 39 & 1.69 & 10 & 11 & 2.01 & $23.1 \mathrm{~ns}$ \\
\hline Mac-1/Mac-3 & 13.2 & 34 & 1.8 & 10.3 & 12 & 2.24 & $22 \mathrm{~ns}$ \\
\hline Mac-2/Mac-3 & 12.3 & 29 & 1.9 & 9.8 & 23 & 1.51 & 20.3 ns \\
\hline Mac-3/Mac-6 & 12.4 & 32 & 1.83 & 10.8 & 20 & 1.47 & $12.9 \mathrm{~ns}$ \\
\hline Mac-1/Mac-8 & 11.2 & 22 & 2.3 & 10.1 & 17 & 1.61 & $9.8 \mathrm{~ns}$ \\
\hline Mac-2/Mac-8 & 12.3 & 25 & 2.06 & 11.3 & 34 & 1.26 & $7.8 \mathrm{~ns}$ \\
\hline Mac-6/Mac-8 & 10.4 & 24 & 2.18 & 11 & 28 & 1.39 & $-5.8 \mathrm{~ns}$ \\
\hline Mac-3/Mac-8 & 10.6 & 18 & 2.31 & 11.3 & 28 & 1.35 & $-6.6 n s$ \\
\hline
\end{tabular}

(-) lack both favorable alleles; (++) carry both favorable alleles; $\mathrm{N}=$ number of RILs in each genotypic class; S.E. = standard error; ns $=$ not significant at the 0.05 probability level.

functional genetic studies will be required to validate this potential role. QTL Mac-2 coinciding with a pectin esterase inhibitor had the highest level of expression and statistical significance of all eleven resistance loci mapped in this study, making it a suitable target for molecular characterization. The significant effect of Mac-2 on Macrophomina resistance will likely result in noticeable and quantifiable change in phenotype sufficient to support its role as a Mendelian factor. Several other QTL mapped in intervals where disease resistance genes were found based on the cowpea genic-SNP markers and synteny with soybean and Medicago. These provide excellent additional candidate gene targets for functional characterization.

This study demonstrated the co-location of Macrophomina resistance and maturity related senescence QTL in the RIL population used for mapping. This finding in cowpea supports the suggested association between early maturity and susceptibility to Macrophomina in other crops $[22,19,23]$. The same pattern of association between earliness and susceptibility to fungal pathogens has been described in other systems as well. Notably, early maturing potato cultivars have been shown to be more susceptible to the late blight disease caused by the fungal pathogen Phytophthora infestans [30-32]. Similar to our findings, QTLs independent of maturity effects have been reported providing the opportunity to breed for early-maturing, late blight-resistant potato cultivars [31,32]. Gebhardt and Valkonen [33] suggested that this association was pleiotropic in nature with the same genes affecting both traits in potato. Interestingly, based on cowpea synteny with soybean and Medicago, both flowering and chlorophyll-metabolism related candidate genes were identified within the two maturity-associated QTL intervals and no apparent disease resistance genes were identified. Although this does not exclude the role of other genes within these QTL intervals, these findings 


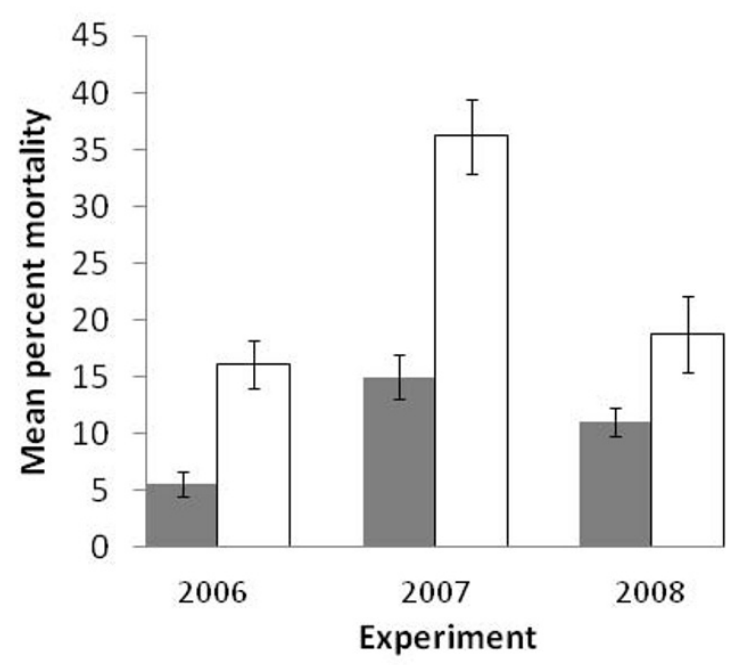

Figure 6 Effect of the combination of Mac-2 and Mac-5 QTL on mean percent plant mortality ( \pm standard error) based on genotypic classes carrying both favorable alleles $(++$, grey bars) and null genotypes (-, white bars) for field experiments in 2006, 2007, and 2008.

may provide additional molecular evidence for the association between early maturity and Macrophomina susceptibility that has been described previously.

The association between early maturity and Macrophomina susceptibility was demonstrated further by the locus carrying Mac-7 and Mat-1. This locus had the largest effect on maturity-induced senescence in a previous study [24], and in the current study, also had the strongest effect on mean percent mortality in both single locus and pair-wise loci analyses. However, the co-location of the maturity and Macrophomina response QTL on this locus may limit its potential application in marker-assisted breeding programs due to tight linkage and possible pleiotropic effects. Breeding for Macrophomina resistant early-maturing varieties that are an important drought escape strategy in parts of West Africa will be complicated by the opposite effects that this locus confers to earliness and Macrophomina resistance. In our simulation study we selected Mac-2 and Mac-5 QTLs as possible target QTLs for pyramiding to improve Macrophomina resistance. The presence of these two QTLs resulted in a doubling in reduction of Macrophominainduced mean percent mortality compared to the presence of either QTL individually. This gain in effect was, however, much less significant (gain of 1\% - 3\%) when we added a third QTL to this combination, suggesting that for breeding purposes, the value of pyramiding three loci compared to two may be markedly diminished.

Genetic overlap was observed in cowpea only between three QTLs mapped in response to drought-induced premature senescence and response to Macrophomina infection. This represented a relatively small proportion of overlap considering the ten QTLs mapped for the drought response [24] and nine QTLs mapped here for response to Macrophomina infection. Whether this colocation is due to linkage or pleiotropy will require further experimentation especially for Mac-5 QTL where both osmotic stress and disease resistance genes were found in the corresponding syntenic soybean genomic region. Similar findings were reported in sorghum where the non-senescence drought tolerance trait was shown to be largely independent from the Macrophomina resistance trait [13]. These findings have important implications for cowpea breeding programs aimed at improving productivity under arid and semi-arid conditions. Macrophomina can cause significant crop losses even under mild drought stress conditions, and introgression of Macrophomina resistance loci should constitute an important component of the breeding schemes targeting genetic improvement with drought tolerance. Furthermore, because early maturing varieties are used as a drought escape strategy in rain-fed production systems, the introgression of non-maturity related resistance loci will be required to mitigate their susceptibility.

\section{Conclusion}

Important sources of Macrophomina phaseolina resistance in cowpea were identified and QTLs for trait determinants of the resistance were located on the EST-derived SNP map. Our observations of candidate genes in the QTL regions with annotations commensurate with the respective phenotype used in revealing the QTL, support this QTL-based approach in identifying genetic determinants of important traits in cowpea. The added resolution provided by synteny with reference legumes makes this approach highly effective. However, because numerous candidates were identified for each QTL, there is a need for effective complementary strategies such as virus-induced gene silencing (VIGS) to validate gene function. Functional analysis also will require a robust greenhouse screening protocol, which based on the inconsistent correlation with field experiments, must be optimized to facilitate such studies. The quantitative nature of Macrophomina resistance highlighted by the number of QTL identified in this study as well as the relatively low contribution of individual loci toward overall resistance makes breeding for this trait difficult. As such, targeting subsets of loci with higher cumulative effects followed by marker-assisted breeding offers an avenue to start incorporating resistance in economically important cultivars. However, the advent of high density marker-based breeding approaches such as whole-genome and genome-wide selection should enhance the ability of breeders to introgress numerous QTL within the context of the same breeding scheme. 


\section{Methods}

Plant material

Fourteen diverse cowpea genotypes were evaluated in two field experiments conducted in 2006 and 2007. The following genotypes were chosen from the University of California, Riverside cowpea germplasm collection: IT98K-499-39, Suvita 2, Mouride, Bambey 21, UCR24, IT98K-556-6, UCR232 (IT82E-18), CB27, CB46, IT93K503-1, UCR779, 24-125B-1, 524B, and IT84S-2049. Lines having an 'IT' prefix are advanced breeding lines developed at the International Institute of Tropical Agriculture (IITA) whereas lines having a 'CB' prefix and UCR24 are cultivars and breeding lines developed in California for production of blackeye-type cowpeas. Genotype 24-125B-1 is an advanced breeding line developed by Institute of Agricultural Research for Development (IRAD) in Cameroon and UCR779 is a landrace accession from Botswana. The accessions represented genotypes with prostrate and erect growth habits, early and late-maturity, and photoperiod sensitivity and insensitivity. These genotypes also belong to high, moderate and low seedling drought tolerance classes as described by Muchero et al [34]. In addition, 108- $\mathrm{F}_{2: 8}$ RILs developed by single seed descent from a cross between the drought tolerant medium-maturing breeding line IT93K-503-1 and drought susceptible early-maturing CB46 genotypes were evaluated in three field and two greenhouse experiments conducted in 2006, 2007, and 2008 for QTL mapping.

\section{Field experiments}

Three field experiments were conducted from June to September of 2006, 2007, and 2008 at the Citrus Research Center-Agricultural Experiment Station (CRCAES) of the University of California Riverside $\left(33^{\circ} 57^{\prime} 54^{\prime \prime} \mathrm{N} ; 117^{\circ} 20^{\prime} 08^{\prime \prime} \mathrm{W}\right)$, USA. The experiments were planted alternately in 2 adjacent field plots with a history of Macrophomina infestation and long-term cultivation of cowpea crops. The soil is classified as an Arlington fine sandy loam (coarse-loamy, mixed, thermic Haplic Durixeralf) [35]. The quick surface-sealing properties of this soil type made it suitable for simulating a gradual and mild drought stress conducive to Macrophomina infection without the confounding effects of overly rapid onset of severe drought stress.

For all field experiments, 200 greenhouse-grown seeds per genotype were distributed equally in 5 replicates, each planted on 5-m-long plots spaced $0.75 \mathrm{~m}$ apart. A subset of 57 RILs, two parental genotypes, and 14 diverse genotypes were evaluated in 2006 and 2007, whereas 108 RILs, which included all the 57 RILs evaluated before, and parental genotypes were evaluated in 2008. The experimental design was a randomized complete block. Drought stress was imposed by growing the crop with only two irrigations, a pre-irrigation about 7 days prior to planting, and a single post-planting irrigation applied 7 days after emergence. These irrigations were applied to furrows and of sufficient duration to fill the soil profile. No further irrigations were applied to the stress treatment. In 2006 and 2007, adjacent blocks having the same experimental material were grown under 'full' irrigation by applying irrigation to field capacity once every seven days for the duration of the active growing period. The well-watered block had 4 replicates and was considered as the Macrophomina plus non-stress treatment, while the stressed field block was considered the Macrophomina plus drought-stress treatment. The same set-up was adopted in 2008 except only RILs and the parental genotypes were evaluated and the well-watered comparison block was not included. Seedling emergence for the Macrophomina plus drought-stress treatment was recorded one week after planting. Macrophomina infection was allowed to occur naturally after which disease evaluation was conducted after 3 to 4 weeks from planting when symptoms of infection started to occur. At this stage, plant mortality counts were recorded for each plot every 7 days until the budding stage. Percent mortality was calculated using the final cumulative mortality counts for each RIL and genotype using the formula: \% mortality $=($ total mortality/total emergence $) \times 100$.

\section{Greenhouse experiments}

(a) Macrophomina isolation and inoculum preparation

Isolation and identification of $M$. phaseolina was carried out using the method described by Aboshosha et al [36] with minor modifications. Briefly, diseased cowpea stems displaying typical ashy stem blight symptoms were collected from the infested CRC-AES field. One$\mathrm{cm}$ stem sections were cut, soaked in concentrated bleach solution for $3 \mathrm{~min}$, and then washed thoroughly under running de-ionized water. Cut sections were placed on sterile potato dextrose agar (PDA) plates and incubated for 3 days at $35^{\circ} \mathrm{C}$. Colony identification was primarily based on morphology and visualization of the characteristic black irregularly shaped microsclerotia. 5-mm-diameter disks were cut from each PDA plate, transferred to a new PDA plate and incubated at $35^{\circ} \mathrm{C}$ for three days. The same procedure was repeated twice. Finally, ten $1-\mathrm{cm}^{2}$ PDA plugs with microsclerotia were kept in sterile deionized water at room temperature for long-term storage. Koch's postulates were fulfilled using the isolated $M$. phaseolina cultures by inoculating greenhouse grown cowpea plants, observing disease development and re-isolating the fungal pathogen from diseased plants.

Inoculum for greenhouse studies was prepared by transferring a $1-\mathrm{cm}^{2}$ plug from long-term storage to a fresh PDA plate. PDA plates were incubated for 5 days 
at $35^{\circ} \mathrm{C}$ for maximum microsclerotia development. PDA with fungal mycelia and microsclerotia was then macerated in sterile water and filtered using quadruple layer cheesecloth to collect the microsclerotial suspension. Microsclerotia were counted under a light microscope and the suspension was adjusted to a final predetermined inoculum concentration of $250 \pm 10$ microsclerotia per ml de-ionized water.

\section{(b) Resistance screening}

Genotypes IT93K-503-1, CB46 and the set of 57 RILs were used in the greenhouse experiments. Greenhouse temperatures were maintained at $30^{\circ} \mathrm{C}$ during the day and $25^{\circ} \mathrm{C}$ during the night. Each experiment was carried out using $878-\mathrm{ml}$ plastic pots filled with $750 \mathrm{~g}$ of steamsterilized UC-MIX B [37] potting media. Each experiment consisted of 4 replicates in a randomized complete block design. Pots were watered to capacity and then planted with 2 greenhouse-grown seeds. Five days after planting, pots were thinned to 1 plant per pot and watered to capacity for the last time. Seven days after the last watering when drought stress was becoming noticeable through leaf curling of unifoliates, two-week old plants were inoculated with a microsclerotia suspension at $250 \pm 10 \mathrm{microsclerotia} / \mathrm{ml}$. Two $5-\mathrm{mm}$ parallel cuts were made $1 \mathrm{~cm}$ below the soil line on each plant stem. 1 $\mathrm{ml}$ inoculum suspension was pipetted directly onto the exposed cuts and immediately covered with potting media. Disease development was evaluated 7 days after inoculation when Macrophomina-induced wilting and stem discoloration started to appear. From this stage, plants were rated every 3 days for the characteristic ashystem symptom by rating the progression from the soil line up the stem of stem discoloration resulting from infection. Symptoms appeared as a deep red to brown lesion that was visible initially just above the soil line. Disease severity was scored on a scale of 1 to $10(0-1=$ no lesion to slight discoloration at soil line; $1-2=$ lesion above soil line but confined below midpoint of first node; $2-3=$ lesion extends up to first internode; $3-4=$ lesion extends beyond first internode but confined to second node; 4-5 = lesion more than half way up second node; 5-6 = lesion extends beyond second internode but confined to third node; 6-7 = lesion extends over third internode; 7-10 lesion extends up to the growing point).

\section{QTL Analysis}

QTL analysis was conducted with the Kruskal-Wallis and Multiple-QTL Model Mapping (MQM) packages of MapQTL 4.0 [38] using a combined AFLP [24] and SNP marker-based [25] genetic linkage map of the IT93K503-1 × CB46 RIL population. Percent mortality data of the RIL population were used to identify QTLs associated with response to infection under field conditions and lesion severity ratings of the RILs were used to identify loci for response to infection under greenhouse conditions. QTLs were considered significant if the same QTL interval was detected in more than one experiment with at least two experiments meeting the Kruskal-Wallis significance threshold or at least one experiment meeting the calculated LOD significance threshold as described below. Significance thresholds were set at the more stringent 0.005 for Kruskal-Wallis as suggested by the authors of the software [38]. Logarithm of odds (LOD) thresholds for MQM analysis were calculated for each experiment and each linkage group using 1000 permutations at the 0.05 significance level. Graphical representation of QTL was done using Map Chart 2.2 software [39].

Placement of Macrophomina resistance QTL on the cowpea high-density consensus map [25] was facilitated by common SNP markers between the IT93K-503-1 $\times$ CB46 map and the consensus map. Candidate gene identification was facilitated by the cowpea consensus map-genic SNPs from the HarvEST:Cowpea browser (http://www.harvest-web.org) as well as Glycine max and Medicago truncatula synteny relationships described by Muchero et al [25]. Cowpea candidate gene ESTs were annotated based on best hit BLAST searches [40] in the EMBL nucleic acid sequence database.

\section{Statistical Analysis}

Data were analyzed for frequency distribution and Spearman Rank correlation using the Statistix 8.0 software [41]. The effect of single and pair-wise QTL combinations on mean percent mortality was done by classifying RILs into genotypic classes with favorable alleles (+ or + + ) and null genotype (- or - ). Class-specific means of percent mortality and standard errors were calculated for each genotypic class. This analysis was conducted using cumulative percent mortality from the 2008 experiment. Heterozygosity at the locus in question was considered as missing data and was excluded from the analysis. Single or double QTL effectiveness was evaluated based on the degree of reduction in percent mortality of the null compared to genotypes with favorable alleles. QTL combinations that resulted in the largest mortality reductions were examined further using data from the 2006 and 2007 field experiments in which 57 RILs were subdivided into genotypic classes as described above. SNP markers 1_0709 (Mac-1), 1_0853 (Mac-2), 1_0604 (Mac3), 1_0201 (Mac-4), 1_0079 (Mac-5), 1_0804 (Mac-6), 1_0678 (Mac-7), and 1_0030 (Mac-8) were used in the genotypic classification exercise based on their association with the respective QTL (Table 2).

\section{Acknowledgements}

This work was supported by the USAID Bean/Cowpea and Dry Grain Pulses CRSP (grants GDG-G-00-02-00012-00 and EDH-A-00-07-00005) and by the 
Generation Challenge Program of the Consultative Group on International Agricultural Research funded through a grant from the Bill and Melinda Gates Foundation.

\section{Author details}

${ }^{1}$ Nematology Dept., University of California-Riverside, 3401 Watkins Drive, Riverside, CA 92521, USA. ${ }^{2}$ Botany and Plant Sciences Dept., University of California-Riverside, 3401 Watkins Drive, Riverside, CA 92521, USA. ${ }^{3}$ Current Address: Plant Systems Biology Group, Bioscience Division, Oak Ridge National Laboratory, 1 Bethel Valley Road, Oak Ridge, TN 37830, USA.

\section{Authors' contributions}

WM, JDE, and PAR conceived and designed the experiment. WM and JDE conducted the experiment. WM, JDE, TJC, and PAR analyzed the data. WM, JDE, TJC, and PAR wrote the paper. All authors read and approved the final manuscript.

Received: 4 February 2010 Accepted: 5 January 2011

Published: 5 January 2011

\section{References}

1. Su G, Suh S-O, Schneider RW, Russin JS: Host specialization in the charcoal rot fungus. Macrophomina phaseolina. Phytopath 2001, 91:120-126.

2. Rusuku G, Buruchara RA, Gatabazi M, Pastor-Corrales MA: Occurrence and distribution in Rwanda of soil borne fungi pathogenic to common bean. Plant Dis 1997, 81:445-449.

3. Bradley CA, del Río LE: First report of charcoal rot on soybean caused by Macrophomina phaseolina in North Dakota. Plant Dis 2003, 87:601.

4. El Araby ME, Kurle JE: First report of charcoal rot (Macrophomina phaseolina) on soybean in Minnesota. Plant Dis 2003, 87:202.

5. Mertely J, Seijo T, Peres N: First report of Macrophomina phaseolina causing a crown rot of strawberry in Florida. Plant Dis 2005, 89:434.

6. Yang XB, Navi SS: First report of charcoal rot epidemics caused by Macrophomina phaseolina in soybean in lowa. Plant Dis 2005, 89:526.

7. Zveibil A, Freeman S: First report of crown and root rot in strawberry caused by Macrophomina phaseolina in Israel. Plant Dis 2005, 89:1014.

8. Gaetán SA, Fernandez L, Madia M: Occurrence of charcoal rot caused by Macrophomina phaseolina on canola in Argentina. Plant Dis 2006, 90:524.

9. Emechebe AM, Lagoke STO: Recent advances in research on cowpea diseases. Challenges and opportunities for enhancing sustainable cowpea production. In Proceedings of the World cowpea Conference III: 4-8 September 2000; International Institute of Tropical Agriculture (IITA) Ibadan Nigeria. Edited by: Fatokun CA, Tarawali SA, Singh BB, Kormawa PM, Tamo M. IITA Ibadan; 2002:94-123.

10. Sanginga N, Dashiell KE, Diels J, Vanlauwe B, Lyasse O, Carsky RJ, Tarawali S, Asafo-Adjei B, Menkir A, Schulz S, Singh BB, Chikoye D, Keatinge D, Ortiz R: Sustainable resource management coupled to resilient germplasm to provide new intensive cereal-grain-legume-livestock systems in the dry savanna. Agric Ecosys Environ 2003, 100:305-314.

11. Ndiaye M: Ecology and management of charcoal rot (Macrophomina phaseolina) on cowpea in the Sahel. PhD Thesis Wageningen University; 2007

12. Hall AE: Breeding for adaptation to drought and heat in cowpea. Eur J Agron 2004, 21:447-454.

13. Tenkouano A, Miller FR, Frederiksen RA, Rosenow DT: Genetics of nonsenescence and charcoal rot resistance in sorghum. Theor Appl Genet 1993, 85:644-648.

14. Singh S, Lodha S: Varietal resistance of cowpea to Macrophomina phaseolina (Tassi) Goid causing dry root-rot and its control. Indian J Agric Sci 1986, 56:552-555.

15. Gaikwad DG, Sokhi SS: Detection of seed rot, root rot and seedling infection in naturally infected cowpea seed in Senegal and their control. Plant Dis Res 1987, 2:127-128.

16. Rao DNV, Shinde VK: Inheritance of charcoal rot resistance in sorghum. J Maharashtra Agric Univ 1985, 10:54-56.

17. Diourte M, Starr JL, Jeger MJ, Stack JP, Rosenow DT: Charcoal rot (Macrophomina phaseolina) resistance and the effects of water stress on disease development in sorghum. Plant Path 1995, 44:196-202.
18. Tesso TT, Claflin LE, Tuinstra MR: Analysis of stalk rot resistance and genetic diversity among drought tolerant sorghum genotypes. Crop Sci 2005, 45:645-652.

19. Smith GS, Carvil ON: Field screening of commercial and experimental soybean cultivars for their reaction to Macrophomina phaseolina. Plant Dis 1997, 81:363-368.

20. Paris RL, Mengistu A, Tyler JM, Smith JR: Registration of soybean germplasm line DT97-4290 with moderate resistance to charcoal rot. Crop Sci 2006, 46:2324.

21. Olaya G, Abawi GS, Weeden NF: Inheritance of resistance to Macrophomina phaseolina and identification of RAPD markers linked to the resistance genes in beans. Phytopath 1996, 86:674-679.

22. Songa W, Hillocks RJ, Mwango'mbe AW, Buruchara R, Konno WK: Screening common bean accessions for resistance to charcoal rot (Macrophomina phaseolina) in Eastern Kenya. Exp Agric 1997, 33:459-468.

23. Edmunds LK: Combined relation of plant maturity, temperature and soi moisture to charcoal stalk rot development in grain sorghum. Phytopath 1964, 54:514-517.

24. Muchero W, Ehlers JD, Close TJ, Roberts PA: Mapping QTL for drought stress-induced premature senescence and maturity in cowpea [Vigna unguiculata (L) Walp]. Theor App/ Genet 2009, 118:849-863.

25. Muchero W, Diop NN, Bhat PR, Fenton RD, Wanamaker S, Pottorff M, Hearne S, Cisse N, Fatokun C, Ehlers JD, Roberts PA, Close TJ: A consensus genetic map of cowpea [Vigna unguiculata $(\mathrm{L})$ Walp] and synteny based on EST-derived SNPs. PNAS USA 2009, 106:18159-18164.

26. Vorwerk S, Somerville S, Somerville C: The role of plant cell wall polysaccharide composition in disease resistance. Trends Plant Sci 2004, 9:203-209.

27. Radha K: The enzymatic activity of Macrophomina phaseoli (Maubl) Ashby. Proc Plant Sci 1953, 38:231-234.

28. Lionetti V, Raiola A, Camardella L, Giovane A, Obel N, Pauly M, Favaron F, Cervone F, Bellincampi D: Overexpression of pectin methylesterase inhibitors in Arabidopsis restricts fungal infection by Botrytis cinerea [W]. Plant Physiol 2007, 143:1871-1880

29. Valette-Collet O, Cimerman A, Reignault P, Levis C, Boccara M: Disruption of Botrytis cinerea pectin methylesterase gene Bcpme1 reduces virulence on several host plants. Mol Plant-Microbe Interact 2003, 16:360-367.

30. Bradshaw JE, Pande B, Bryan GJ, Hackett CA, McLean K, Stewart HE, Waugh R: Interval mapping of quantitative trait loci for resistance to late blight [Phytophthora infestans (Mont.) de Bary], height and maturity in a tetraploid population of potato (Solanum tuberosum subsp. tuberosum). Genetics 2004, 168:983-995.

31. Śliwka J, Jakuczun H, Lebecka R, Marczewski W, Gebhardt C, ZimnochGuzowska E: The novel, major locus Rpi-phu1 for late blight resistance maps to potato chromosome IX and is not correlated with long vegetation period. Theor Appl Genet 2006, 113:685-695.

32. Visker MHPW, Heilersig HJB, Kodde LP, Van de Weg WE, Voorrips RE, Struik PC, Colon LT: Genetic linkage of QTLs for late blight resistance and foliage maturity type in six related potato progenies. Euphytica 2005, 143:189-199.

33. Gebhardt C, Valkonen JPT: Organization of genes controlling disease resistance in the potato genome. Annu Rev Phytopathol 2001, 39:79-102.

34. Muchero W, Ehlers JD, Roberts PA: Seedling stage drought-induced phenotypes and drought-responsive genes in diverse cowpea genotypes. Crop Sci 2008, 48:541-552.

35. Nielsen $\mathrm{CL}$, Hall AE: Responses of cowpea (Vigna unguiculata (L) Walp) in the field to high night air temperature during flowering. II. Plant responses. Field Crop Res 1985, 10:181-196

36. Aboshosha SS, Atta Alla SI, El-Korany AE, El-Argawy E: Characterization of Macrophomina phaseolina isolates affecting sunflower growth in ElBehera governorate. Egypt Int J Agri Biol 2007, 9:807-815.

37. Matkin OA, Chandler PA: The UC-type soil mixes. In The UC system for producing healthy container-grown plants. Edited by Baker KF. Agricultural Publications University of California Berkeley 1957, 68-85.

38. Van Ooijen JW, Boer MP, Jansen RC, Maliepaard C: MapQTL ${ }^{\otimes} 4.0$ software for the calculation of QTL positions on genetic maps. Plant Research International Wageningen, the Netherlands 2002.

39. Voorrips RE: MapChart: Software for the graphical presentation of linkage maps and QTLs. J Heredity 2002, 93:77-78. 
40. Altschul SF, Gish W, Miller W, Myers EW, Lipman DJ: "Basic local alignment search tool". J Mol Biol 1990, 215:403-410.

41. Analytical software: Statistix 8 user's manual: Analytical software Tallahassee FL; 2003.

doi:10.1186/1471-2164-12-8

Cite this article as: Muchero et al:: Genic SNP markers and legume synteny reveal candidate genes underlying QTL for Macrophomina phaseolina resistance and maturity in cowpea [Vigna unguiculata (L) Walp.]. BMC Genomics 2011 12:8.

Submit your next manuscript to BioMed Central and take full advantage of:

- Convenient online submission

- Thorough peer review

- No space constraints or color figure charges

- Immediate publication on acceptance

- Inclusion in PubMed, CAS, Scopus and Google Scholar

- Research which is freely available for redistribution

Submit your manuscript at www.biomedcentral.com/submit
C Biomed Central 